\title{
Elongated Styloid Process: Mapping the incidence in Greek population
}

\author{
Vasilopoulos Anastasios *1, Tsoucalas Gregory ${ }^{2}$, Thomaidis Vasileios ${ }^{3}$. \\ ${ }^{*}$ Department of Anatomy, School of Medicine, Democritus University of Thrace, Alexandroupolis \\ Greece.
}

${ }^{2}$ Department of Anatomy, School of Medicine, Democritus University of Thrace, Alexandroupolis Greece.

${ }^{3}$ Department of Anatomy, School of Medicine, Democritus University of Thrace, Alexandroupolis Greece.

\section{ABSTRACT}

Background: Styloid process (SP) is a needle shaped projection of the temporal bone, which lies in close proximity to several important anatomical structures of the head and neck. It attracts the attention of anatomists, otolaryngologists and head and neck surgeons, as an abnormally long SP is linked with a clinical condition known as Eagle Syndrome. There are numerous studies in the literature investigating morphometric characteristics of SP, including its length in different populations. The aim of this study is to investigate the incidence of SP elongation in Greek population and to construct an epidemiologic map showing the incidence of SP elongation across different regions of Greek territory.

Materials and methods: Two hundred and nine skulls retrieved from cemeteries across Greece were meticulously examined. Ninety-four male skulls and one-hundred and fifteen females, all of Hellenic origin. SP length was measured from the lowest inner point of the surface between the SP and the stylomastoid foramen to its tip, utilizing a digital caliper and a steel wire. Data from this study were statistically analyzed and combined with data from other studies in Greek population in order to construct a detailed epidemiologic map.

Results: The mean length was $27.26 \pm 5.89 \mathrm{~mm}$ for the left and $27.84 \pm 6.31 \mathrm{~mm}$ for the right SP. In males $36.4 \%$ of the left and $37.8 \%$ of the right SP were elongated. In females the incidence of SP elongation was $14.3 \%$ and $15.5 \%$ for left and right side respectively. Statistically significant association was observed between gender and SP length but not between age and SP length.

Conclusion: This study enriches the literature by adding information about elongated SP incidence in Greek population. It reviews the existing studies about SP length in Greeks and presents an epidemiologic map showing the incidence of SP elongation across different regions in Greece.

KEY WORDS: Skull, Eagle syndrome, Hellenic population, Elongated Styloid Process.

Corresponding Author: Vasilopoulos Anastasios, Department of Anatomy, School of Medicine, Democritus University of Thrace, Alexandroupolis Greece. E-Mail: tasosb14@gmail.com

Access this Article online

\section{Quick Response code}

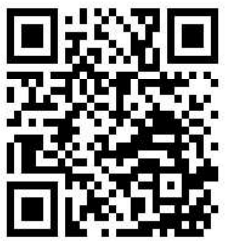

DOI: $10.16965 /$ ijar.2021.124

Journal Information

\section{International Journal of Anatomy and Research}

ISSN (E) 2321-4287 | ISSN (P) 2321-8967

https://www.ijmhr.org/ijar.htm

DOI-Prefix: https://dx.doi.org/10.16965/ijar

\section{Article Information}

Received: 16 Mar 2021

Peer Review: 16 Mar 2021

Revised: None
Accepted: 17 Apr 2021

Published (O): 11 May 2021

Published (P): 05 Jun 2021

\section{INTRODUCTION}

Styloid process (SP) of the cranium (from the Greek word stylos, óôyëïò: pillar) is a columnar shaped, cylindrical thin bony projection of the temporal bone. SP emerges from the base of the skull, right anteriorly to the stylomastoid foramen and laterally to the jugular foramen [1]. Embryologically, it originates from Reichert's cartilage, which derives from the second brachial arch. During 
evolution, Reichert's cartilage separates into four parts: tympanohyal, stylohyal, ceratohyal and hypohyal. It is from the tympanohyal part that the base of SP is created. From the Stylohyal part arise the shaft of the process and the proximal part of the stylohyal ligament. SP hosts the origin point of three muscles and two ligaments: Stylohyoid, styloglossus and stylopharyngeus muscles and stylohyoid and stylomandibular ligaments. Those anatomic structures contribute to the mobility of the tongue, pharynx, larynx, hyoid bone and mandible. Numerous important human structural parts lie in close proximity to the SP. Internal carotid artery, maxillary artery, internal jugular vein, glossopharyngeal nerve, vagus nerve, accessory nerve, branches from trigeminal and facial nerves lie medially to the SP. Occipital artery and hypoglossal nerve lie laterally to the process. [1,2]

SP length presents a large variability, ranging from 5 to $75 \mathrm{~mm}$ [3]. A scientific global consensus defines that a SP longer than $30 \mathrm{~mm}$ is considered elongated (Figures 1 and 2) [1]. Calcification of the Stylohyoid ligament appears as a common phenomenon and could cause difficulties for such a SP to be distinguished from an elongated one [4]. Its exact pathophysiological mechanism is not completely understood. Various studies have proposed several mechanisms, including post traumatic scarring, developmental abnormalities and bone homeostasis disorders [5]. An elongated SP (ESP) or a calcified stylohyoid ligament could apply mechanical pressure to any adjacent anatomical structures, leading to a condition known as Eagle's Syndrome (ES), a rare condition described by Eagle in 1937 [6]. ES may present with a plethora of symptoms, such as ear pain, dysphagia, odynophagia, neck pain, sensation of foreign body in the pharynx and pain when turning the head or yawning $[5,7]$. Severe symptomatology, like ischemic stroke incidents by compression of the internal carotid artery, carotid artery dissection and carotid stent fractures have been also reported as a result of an ESP [5].

Numerous studies in the international literature exist, concerning the incidence of SP elongation, focused on different populations, including Indian, Turkish, Brazilian, Serbian and Italian [3,8-11]. A thorough search in medical databases PubMed and Scopus, revealed only 2 studies based upon the Greek population. The first one was published by Natsis et al, while the second from Zokaris et al, including samples from Thessaloniki and Athens respectively $[12,13]$.

This study aims: a) To study the length of the SP and the incidence of ESP by obtaining samples from several regions across Greece, b) To create an epidemiologic map of ESP in Greece, combining data from both this study and the previous studies on SP in Greek population. c) To enrich the available data with a more detailed view of ESP incidence in Greece.

\section{MATERIALS AND METHODS}

Two hundred and nine adult dry skulls were thoroughly examined, 94 male (45.0\%) and 115 females (55.0\%). The study specimens, all of Caucasian (Hellenic) origin, were retrieved from cemeteries located in several Greek regions, including Pelloponisos, Thessalia, Crete and Thrace.

Skulls presenting obvious pathological lesions (tumors, fractures), damages from the taphonomic procedures and children skulls were excluded from the study. Sex definition for each specimen was recovered by the cemetery records. Specimen inspection and examination were authorized by the Research Ethics Committee of the Democritus University of Thrace and the local Municipal Authorities. Specimen collection was random to eliminate any bias. All measurements were conducted by two independent researchers for the accuracy of the results to be ensured. Data analysis for inter-observer error showed a mean difference between the first and second measurement of $\pm 0.5 \mathrm{~mm}$, indicating that there is no relevant difference between the two series of measurements.

To measure SP length, this study used a stable osseous landmark as close as possible to the emergence of the process from the skull base. Thus, as the starting point was considered the lowest inner point of the surface between the SP and the stylomastoid foramen, and as the ending point the tip of the SP. (Figure 3) A steel 
wire was set on the starting point across the longitudinal axis of SP to its tip, following every existing curvature of the process. Then the wire was cut, straightened and measured with a digital caliper of $\pm 0.01 \mathrm{~mm}$ accuracy.

Statistical analysis of the data was performed using the Statistical Package for the Social Sciences (SPSS), version 19.0 (IBM). The mean age of the adults was $67.21 \pm 14.82$ years (range: 28-97), while skulls were categorized into the following age-groups: $\leq 45$ years of age (50 skulls, 23.9\%), 46-65 (66 skulls, 31.6\%) and older than 65 years (93 skulls, $44.5 \%$ ). Due to SP fractures in 55 skulls, its length was measured only on one side. Therefore, 186 left-sided and 177 right-sided processes were measured.

Data collected during this study were combined with data from the existing studies on Greek population to construct a map that depicts the incidence of SP elongation per region. (Figure 4).

Fig. 1: An elongated (length: $49 \mathrm{~mm}$ ) SP on a dry skull.

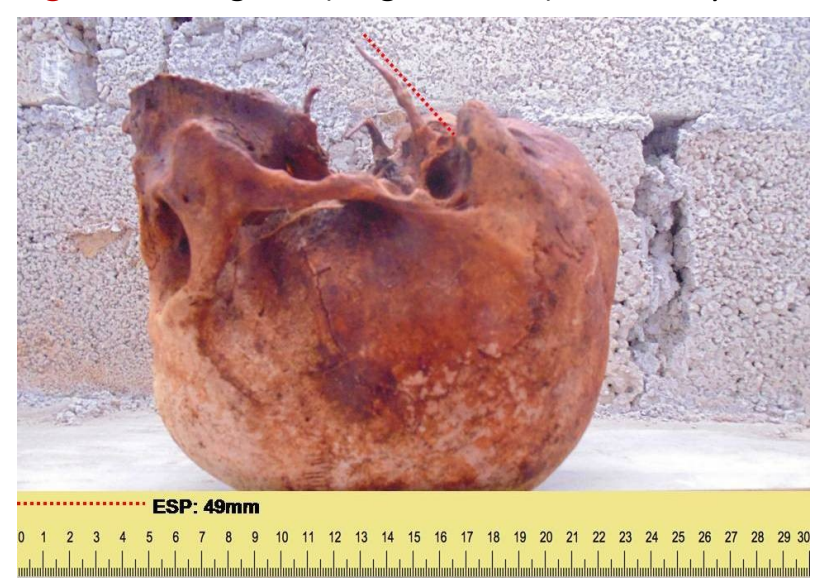

Fig. 2: Panoramic radiographs depicting SP elongation unilaterally and bilaterally.

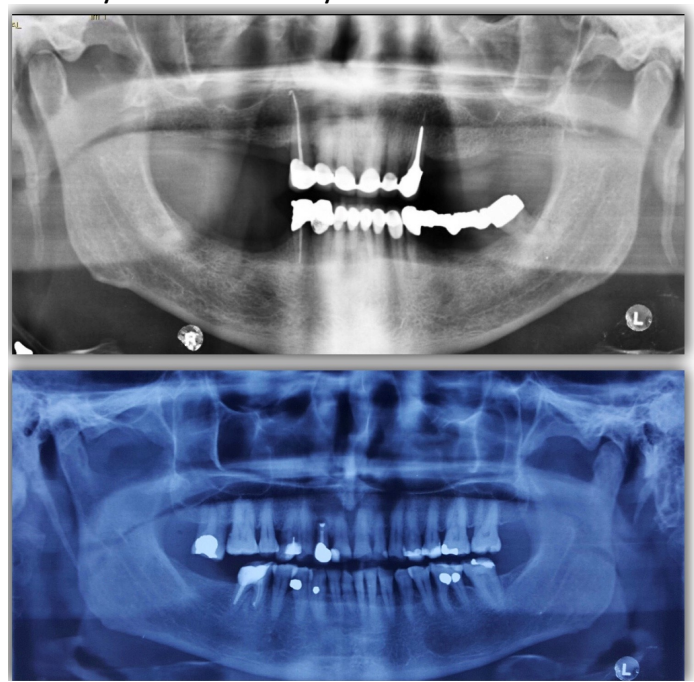

Fig. 3: Measuring SP length. Starting point: the lowest inner point of the surface between the SP and the stylomastoid foramen (red arrow). Ending point: the tip of the SP.

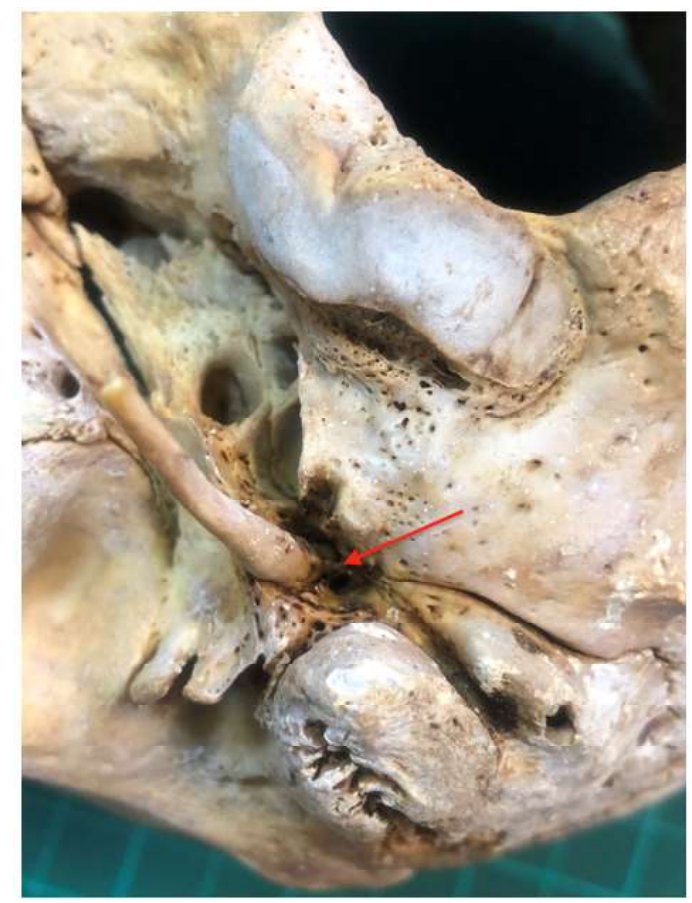

Fig. 4: A map showing Greek geography, skull number and elongated SP per region.

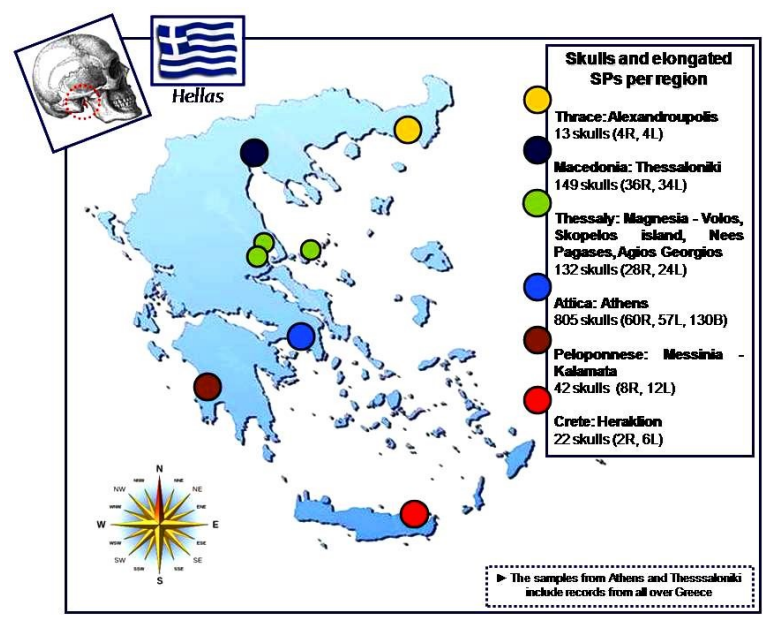

\section{RESULTS}

Based on the measurements obtained, descriptive statistics for the length of styloid processes were calculated for left and right side separately (Table 1). The lengths of the left-sided styloid processes varied from 11.81 to $43.90 \mathrm{~mm}$ with a mean value of $27.26 \pm 5.89$ $\mathrm{mm}$. The lengths of the right-sided styloid processes varied from 12.16 to $46.00 \mathrm{~mm}$ with a mean value of $27.84 \pm 6.31 \mathrm{~mm}$; there was no statistically significant difference between left and right styloid process lengths $(p=0.531)$.

Regarding to gender, it was observed that the males had statistically significant greater 
Vasilopoulos Anastasios, Tsoucalas Gregory, Thomaidis Vasileios. Elongated Styloid Process: Mapping the incidence in Greek population.

Table 2: Length of left and right styloid

Table 1: Length of left and right styloid processes.

\begin{tabular}{lccc}
\hline & \multicolumn{2}{c}{ Side } & \multirow{2}{*}{ P value } \\
\cline { 2 - 3 } & Left & Right & \\
\hline $\mathbf{N}$ & 186 & 177 & \\
Styloid process $(\mathbf{m m})$ & & & 0.531 \\
Mean \pm SD & $27.26 \pm 5.89$ & $27.84 \pm 6.31$ & \\
Min & 11.81 & 12.16 & \\
$\mathbf{2 5}^{\text {th }}$ percentile & 24.38 & 25.31 & \\
Median & 26.69 & 26.51 & \\
$\mathbf{7 5}^{\text {th }}$ percentile & 29.99 & 29.88 & \\
Max & 43.9 & 46 & \\
\hline
\end{tabular}

\begin{tabular}{|c|c|c|c|}
\hline & \multicolumn{2}{|c|}{ Gender } & \multirow{2}{*}{$P$ value } \\
\hline & Females & Males & \\
\hline Left styloid process $(\mathrm{mm})$ & & & 0.022 \\
\hline $\mathbf{N}$ & 98 & 88 & \\
\hline Mean \pm SD & $26.33 \pm 5.91$ & $28.30 \pm 5.71$ & \\
\hline Min & 11.81 & 15.27 & \\
\hline $25^{\text {th }}$ percentile & 23.21 & 24.78 & \\
\hline Median & 26.32 & 27.14 & \\
\hline $75^{\text {th }}$ percentile & 27.12 & 31.07 & \\
\hline Max & 43.9 & 41.76 & \\
\hline Right styloid process (mm) & & & $<0.001$ \\
\hline $\mathbf{N}$ & 103 & 74 & \\
\hline Mean \pm SD & $26.41 \pm 5.89$ & $29.82 \pm 6.39$ & \\
\hline Min & 12.16 & 13.62 & \\
\hline $25^{\text {th }}$ percentile & 24.52 & 26.39 & \\
\hline Median & 26.12 & 29 & \\
\hline $75^{\text {th }}$ percentile & 26.93 & 31.5 & \\
\hline Max & 46 & 45.9 & \\
\hline$P$ value & $0.806(n=86)$ & $0.056(n=68)$ & \\
\hline
\end{tabular}

Table 3: Length of left and right styloid processes according to age.

\begin{tabular}{|c|c|c|c|c|}
\hline & \multicolumn{3}{|c|}{ Age } & \multirow{2}{*}{$P$ value } \\
\hline & $\leq 45$ years & $46-65$ years & $>65$ years & \\
\hline $\begin{array}{l}\text { Left styloid process } \\
(\mathrm{mm})\end{array}$ & & & & 0.131 \\
\hline $\mathbf{N}$ & 45 & 60 & 81 & \\
\hline Mean \pm SD & $26.27 \pm 4.78$ & $26.69 \pm 5.76$ & $28.24 \pm 6.43$ & \\
\hline Min & 13.94 & 11.81 & 15.27 & \\
\hline $25^{\text {th }}$ percentile & 23.77 & 23.32 & 24.95 & \\
\hline Median & 26.31 & 26.71 & 26.72 & \\
\hline $75^{\text {th }}$ percentile & 27.73 & 30.16 & 30.11 & \\
\hline Max & 39.56 & 41.75 & 43.9 & \\
\hline $\begin{array}{l}\text { Right styloid process } \\
(\mathrm{mm})\end{array}$ & & & & 0.205 \\
\hline $\mathbf{N}$ & 41 & 57 & 79 & \\
\hline Mean \pm SD & $26.87 \pm 4.18$ & $27.24 \pm 5.50$ & $29.82 \pm 6.39$ & \\
\hline Min & 13.89 & 13.62 & 12.16 & \\
\hline $25^{\text {th }}$ percentile & 25.63 & 25.55 & 25.11 & \\
\hline Median & 26.46 & 26.51 & 26.53 & \\
\hline $75^{\text {th }}$ percentile & 28.12 & 29.78 & 30 & \\
\hline Max & 38.75 & 41.01 & 46 & \\
\hline$P$ value & $0.157(n=36)$ & $0.487(n=51)$ & $0.129(n=67)$ & \\
\hline
\end{tabular}


Table 4: Elongated styloid processes according to gender and age.

\begin{tabular}{lcccc}
\hline & $\begin{array}{c}\text { Elongated left } \\
\text { styloid process }\end{array}$ & P value & $\begin{array}{c}\text { Elongated right } \\
\text { styloid process }\end{array}$ & P value \\
\hline $\mathbf{N}$ & $46(24.7)$ & & $44(24.9)$ & \\
Gender & $14(14.3)$ & $<0.001$ & & $\mathbf{0 . 0 0 1}$ \\
Females & $32(36.4)$ & & $16(15.5)$ & \\
Males & & 0.416 & $28(37.8)$ & \\
Age & $8(17.8)$ & & $9(22.0)$ & \\
$\leq 45$ years & $15(25.0)$ & & $14(24.6)$ & \\
$\mathbf{4 6}$ - 65 years & $\mathbf{2 3 ( 2 8 . 4 )}$ & & $\mathbf{2 1 ( 2 6 . 6 )}$ & \\
$>$ 65 years & & &
\end{tabular}

Table 5: Elongated Styloid Process per region.

\begin{tabular}{|c|c|c|c|c|c|c|}
\hline \multirow{2}{*}{ Region } & \multirow{2}{*}{ Skulls } & \multicolumn{2}{|c|}{ Total SP* } & \multicolumn{3}{|c|}{ Elongated } \\
\hline & & Right & Left & Right & Left & Bilateral \\
\hline $\begin{array}{c}\text { Magnesia: Volos, Skopelos, Nees Pagases, } \\
\text { Agios Georgios }\end{array}$ & 132 & 126 & 120 & $28(22.2 \%)$ & $24(20 \%)$ & - \\
\hline Peloponnese: Messinia -Kalamata & 42 & 26 & 38 & $8(30.7 \%)$ & $12(31.6 \%)$ & - \\
\hline Crete: Heraklion & 22 & 18 & 18 & $2(11.1 \%)$ & $6(33.3)$ & - \\
\hline Thrace: Alexandroupolis & 13 & 6 & 10 & $4(60 \%)^{*}$ & $4(40 \%)^{*}$ & - \\
\hline Attica: Athens [13] & 805 (OPG's) & 653 & 627 & 60 (only right) & 57 (only left) & $130(16.14 \%)$ \\
\hline Macedonia: Thessaloniki [12] & 149 & 127 & 135 & $36(28.3 \%)$ & $34(25.2 \%)$ & - \\
\hline
\end{tabular}

*SP: Styloid Process *Small sample

styloid process lengths than the females on both the left $(p=0.022)$ and right $(p<0.001)$ sides. There was no statistically significant difference between right and left styloid process lengths among females $(p=0.806)$ and males $(p=0.056)$ (Table 2$)$. There was also no statistically significant correlation between age and SP length neither on the left $(p=0.131)$ nor on the right $(p=0.205)$ side. (Table 3$)$.

Trying to use a methodology close to other studies in Greek population, SP length normal values were characterized using percentiles, as proposed by Natsis et al. [12]. In the sequence, any styloid process longer than the $75^{\text {th }}$ percentile was considered elongated. The incidence of elongated SP in relation to gender and age is given in Table 4. SP elongation was more frequent in males compared to females on both the left $(O R=3.43,95 \%$ $\mathrm{Cl}=1.68-7.00, \mathrm{p}<0.001)$ and right $(\mathrm{OR}=3.31,95 \%$ $\mathrm{Cl}=1.638-6.74, \mathrm{p}<0.001)$ sides. There was no statistically significant correlation between the incidence of SP elongation and age neither on the left $(p=0.416)$ nor on the right ( $p=0.855)$ side.

The incidence of ESP per region are presented in Table 5. Greek geography and skull number per region are presented in Figure 4.

\section{DISCUSSION}

Various measuring methods have been used for the length calculation of the SP. There are studies in the literature referring to measurements on dry skulls $[9,11]$, panoramic radiographs $[10,14]$, Computerized Tomography $(C T)$ images $[3,15]$, or cadavers [11]. Panoramic radiographs present an excellent image to measure SP length in living patients and provide the ability to assess the length of both the right and left SP, which is not always possible on dry skulls. Radiography software also makes possible to assess radiographs from the archives, giving the opportunity of a large sample to be obtained. However, it involves extra parameters that may make the procedure more complex, such as the magnification factor [4] or any existing distortion of the radiographic system [13]. On the contrary, dry skulls provide direct on hand access to the SP and at the same time it is possible to measure the entire length of the process following its curves. Nonetheless, during sample collection and examination many skulls appeared with one or none of the processes intact due to damages during the taphonomic manipulation of the bones, decreasing the sample size. Moreover, as several skulls appeared with only one intact 
SP, this study encountered great difficulty to calculate the incidence of bilateral SP elongation. Two methods have been used to measure SP length in Greek population. Natsis et al, [12] used the lowest inner point of the floor of external acoustic meatus (EAM) as a starting point and following the longitudinal axis of SP to its tip. Zokaris et al, [13] used a method proposed by Jung et al [14] and the method of Natsis et al and compared findings. Jung et al, used as an anatomical landmark the center of a circle between the lower margin of the tympanic plate of the temporal bone and the SP, which represents the free part of the process [14]. The method proposed by Natsis et al allows to measure SP length from its anatomical basis, its origin from the skull base, but requires removal of the vaginal process and the outer part of EAM. Other authors initiate measurements "from the point where it leaves the temporal plate" [8], or from the point of its emergence [9] without mentioning any stable osseous landmarks. This study used a measuring protocol taking under consideration the anatomical origin of SP while respecting the skull bone integrity. We approached SP posteriorly, considering the lowest inner part of the surface between SP and stylomastoid foramen as our starting point, as close as possible to the emersion point of the process. The steel wire was bent following each curvature of the process and straightened after being cut, creating "a whole length" line of SP to be measured.

Specimen collection for this study was performed in several cemeteries across Greece in order for a random sample from Greek population to be obtained and for a map showing the incidence of ESP in several regions to be created. For the creation of the map, samples from Natsis et al were recorded as being from the region of Thessaloniki [12]. Samples of Zokaris et al were recorded to be from Athens, Attiki area. However, Zokaris sample included students of the Hellenic Air Force, with a origin from all over Greece, just living in Athens as apprentices [13].

The mean length of the left SP was $28.30 \pm$ 5.71 for males and $26.33 \pm 5.91$ for females.
Mean length for the right SP was $29.82 \pm 6.39$ for males and $26.41 \pm 5.89$ for females. Our results come in agreement with the results of Zokaris et al, who measured SP starting from the external acoustic meatus [13] and Petrovic et al. [3] In other studies the mean length was calculated in smaller or larger values. ÿbVadgaonkar et al, reported for Indian population median values ÿp17.8 $\pm 9.3 \mathrm{~mm}$ for the right and $18.2 \pm 5.6 \mathrm{~mm}$ for the left side, while ÿpRathva et al, for the Indian population once more, noted a mean SP length ÿp43.8 $\pm 11.1 \mathrm{~mm}$ for the right and $43.5 \pm 10.4 \mathrm{~mm}$ for left side (9).

There is a debate in the literature on the normal SP length. The length of $30 \mathrm{~mm}$ or $3 \mathrm{~cm}$ is most frequently used by consensus as the maximum normal value for SP length [7]. Eagle in 1937 reported normal SP length between 2.5 and $3.5 \mathrm{~cm} \mathrm{[6].} \mathrm{Jung} \mathrm{et} \mathrm{al,} \mathrm{proposed} 45 \mathrm{~mm}$ as a starting point for SP elongation. Present study considers as maximum normal length of the SP the $75^{\text {th }}$ percentile, as proposed by Natsis et al.[12]. The maximum SP length according to our data is 29.99 for the left and 29.88 for the right side, which comes in agreement with the generally used limit of $30 \mathrm{~mm}$ and is also close to the maximum value of $33 \mathrm{~mm}$ reported by Íatsis et al [12]. Slight differences are considered to emerge from differences in measuring protocols.

A series of studies describe the frequency of SP elongation. ESP incidence varies from $4 \%$ to $84.4 \%$ [7]. According to the data of this study, ESP incidence in Greek population was calculated $24.7 \%$ and $24.9 \%$ for left and right side respectively. In males, $36.4 \%$ of the left SP and $37.8 \%$ of the right SP were elongated. In females the incidence was $14.3 \%$ and $15.5 \%$ for left and right side respectively. Zokaris et al. found that $30.6 \%$ of SPs were elongated, $16.14 \%$ bilaterally and $14.53 \%$ unilaterally. In males he found $33.12 \%$ of SPs to be elongated: $18.16 \%$ bilaterally and $14.65 \%$ unilaterally $\mathrm{He}$ reported ESP incidence in females to be $20 \%: 12.6 \%$ unilaterally and $7.3 \%$ bilaterally [13]. Natsis et al. found ESP incidence to be $28.3 \%$ for the right and $25.2 \%$ for the left side [12].

No statistically significant difference between 
right and left SP is to be reported by this study, while the same apply for the correlation between age and ESP. However, a statistically significant difference in SP length between males and females on both the left $(p=0.022)$ and right $(p<0.001)$ sides was observed. SP length was greater in males. Our results concur with Balcioglu et al, and Petrovic et al, [3] who also reported statistically significant differences among males and females in all age groups [11]. The study by Zokaris et al, also supports significantly higher mean values in males [13]. Other studies support that there is not statistically important difference between gender and SP length $[4,8,12]$.

Elongated styloid process is frequently associated with Eagle Syndrome (ES), a clinical condition presetting various clinical manifestations and a broad differential diagnosis, including migraine, trigeminal neuralgia, chronic tonsillitis, psychosomatic diseases and oropharyngeal tumors [7]. ES may be misdiagnosed, causing discomfort for the patient, or leading to prolonged wrong treatments [16]. ES is also linked to serious complications, such as ischemic transient stroke, carotid artery dissections and carotid stent fractures [5]. Sudden death has also been reported [17]. Clinical practitioners should be aware of an ES case for fatal results to $e$ avoided.

\section{CONCLUSION}

$\mathrm{SP}$, is clinically an important anatomical structure, globally studied by many researchers. Knowledge of the ESP incidence may provide help to various clinicians to include ES in differential diagnosis when managing cases of head and neck pain. This study, investigated the incidence of SP elongation in Greece, reviewed the existing studies about SP elongation in Greek population and created a map showing ESP incidence in several Greek regions.

\section{ABBREVIATIONS}

SP - Styloid Process

ESP - Elongated Styloid Process

ES - Eagle's Syndrome

Conflicts of Interests: None

\section{REFERENCES}

[1]. Fusco DJ, Asteraki S, Spetzl RF. Eagle's syndrome: Embryology, anatomy, and clinical management. Acta Neurochir 2012;154:1119-26.

[2]. Abuhaimed AK, Menezes RG. Anatomy, Head and Neck, Styloid Process. StatPearls 2019.

[3]. Petroviæ S, Jovanoviæ I, Ugrenoviæ S, Radovanoviæ Z, Pešiæ Z, Vuèkoviæ I, et al. Morphometric analysis of the stylohyoid complex. Surg Radiol Anat 2017;39:52534.

[4]. Ferrario VF, Sigurta D, Daddona A, Dalloca L, Miani A, Tafuro F, et al. Calcification of the stylohyoid ligament: Incidence and morphoquantitative evaluations. Oral Surg Oral Med Oral Pathol 1990;69:524-9.

[5]. Badhey A, Jategaonkar A, Anglin Kovacs AJ, Kadakia S, De Deyn PP, Ducic $Y$, et al. Eagle syndrome: A comprehensive review. Clin Neurol Neurosurg 2017;159:348.

[6]. Eagle WW. Elongated Styloid Processes: Report of Two Cases. Arch Otolaryngol 1937;25:584-7.

[7]. Piagkou MN, Anagnostopoulou S, Kouladouros K, Piagkos G. Eagle's syndrome: A review of the literature. Clin Anat 2009;22:545-58.

[8]. Gracco A, Stefani A De, Bruno G, Balasso P, AlessandriBonetti G, Stellini E. Elongated styloid process evaluation on digital panoramic radiograph in a North Italian population. J Clin Exp Dent 2017;9:400-4.

[9]. Vadgaonkar R, Murlimanju BV, Prabhu LV, Rai R, Pai $M M$, Tonse $M$, et al. Morphological study of styloid process of the temporal bone and its clinical implications. Anat Cell Biol 2015;48:195.

[10]. Vieira EM, Guedes OA, Morais SD, Musis CR, Albuquerque PA, Borges ÁH. Prevalence of elongated styloid process in a central brazilian population. J Clin Diagn Res 2015;9:90-2.

[11]. Balcioglu HA, Kilic C, Akyol M, Ozan H, Kokten G. Length of the styloid process and anatomical implications for Eagle's syndrome. Folia Morphol (Warsz) 2009;68:26570.

[12]. Natsis K, Repousi E, Noussios G, Papathanasiou E, Apostolidis S, Piagkou M. The styloid process in a Greek population: an anatomical study with clinical implications. Anat Sci Int 2014;90:67-74.

[13]. Zokaris N, Siska I, Natsis K, Piagkou M, Lazaridis N, Skolka $A$, et al. Investigation of the styloid process length in a Greek population. Folia Morphol (Warsz) 2019;78:378-88.

[14]. Jung T, Tschernitschek $H$, Hippen $H$, Schneider B, Borchers L. Elongated styloid process: When is it really elongated? Dentomaxillofac Radiol. 2004;33:11924.

[15]. Ayyildiz VA, Senel FA, Dursun A, Ozturk K. Morphometric examination of the styloid process by $3 \mathrm{D}-\mathrm{CT}$ in patients with Eagle syndrome. Eur Arch Otorhinolaryngol 2019;276:3453-9.

[16]. Mayrink G, Figueiredo EP, Sato FR, Moreira RW. Cervicofacial pain associated with Eagle's syndrome misdiagnosed as trigeminal neuralgia. Oral Maxillofac Surg. 2012;16:207-10.

[17]. Kumar P, Rayamane AP, Subbaramaiah M. Sudden death due to eagle syndrome: A case report. Am J Forensic Med Pathol 2013;34:231-3. 